\title{
Prophylactic steroid administration for strictures after endoscopic resection of large superficial esophageal squamous cell carcinoma
}

Authors

Institutions
Tomohiro Kadota ${ }^{1,2}$, Tomonori Yano', Tomoji Kato', Maomi Imajoh¹, Masaaki Noguchi', Hiroyuki Morimoto', Shozo Osera ${ }^{1}$, Yusuke Yoda ${ }^{1}$, Yasuhiro Oono ${ }^{1}$, Hiroaki lkematsu' ${ }^{1}$, Atsushi Ohtsu ${ }^{2,3}$, Kazuhiro Kaneko ${ }^{1}$

\begin{abstract}
'Department of Gastroenterology, Endoscopy Division, National Cancer Center Hospital East, Kashiwa, Chiba, Japan ${ }^{2}$ Course of Advanced Clinical Research of Cancer, Juntendo University Graduate School of Medicine, Tokyo, Japan

${ }^{3}$ Exploratory Oncology Research \& Clinical Trial Center, National Cancer Center, Kashiwa, Chiba, Japan
\end{abstract}

submitted 4. June 2016 accepted after revision 9. September 2016

\section{Bibliography}

Dol http://dx.doi.org/ 10.1055/s-0042-118291 Published online: 21.11.2016 Endoscopy International Open 2016; 04: E1267-E1274

(c) Georg Thieme Verlag KG Stuttgart · New York E-ISSN 2196-9736

\section{Corresponding author} Tomonori Yano

Department of

Gastroenterology

Endoscopy Division

National Cancer Center

Hospital East

6-5-1, Kashiwanoha

Kashiwa, Chiba 277-8577 Japan

Phone: +81-4-7133-1111

Fax: 04-7134-6865

toyano@east.ncc.go.jp
License terms

(이요
Background and study aims: One of the major complications after endoscopic resection (ER) for large superficial esophageal squamous cell carcinoma (ESCC) is benign esophageal stricture, which can reduce quality of life even if ESCC achieves a cure without organ resection. Recently, steroid administration has been reported as a prophylactic treatment to prevent esophageal strictures. This retrospective study evaluated the stricture rate according to the different width of mucosal defects due to ER and compared it to that seen with prophylactic steroid administration.

Patients and methods: Between June 2007 and December 2013, we enrolled patients with ESCC who had 3/4 or larger circumferential mucosal defects due to ER. In December 2009, steroid injections (triamcinolone acetonide $50 \mathrm{mg}$ ) into the ulcer bed due to ER were introduced. Beginning in November 2012, we commenced oral steroid administration (prednisolone $30 \mathrm{mg} /$ day, tapered gradually for 8 weeks) in addition to steroid injection. Patients were classified into 3 groups accord-

\section{Introduction \\ $\nabla$}

Endoscopic resection (ER) including endoscopic mucosal resection (EMR) and endoscopic submucosal dissection (ESD) is a standard treatment for superficial esophageal squamous cell carcinoma (ESCC) [1-3]. In particular, ESD has recently been widely adopted for the treatment of superficial ESCC because en bloc complete resection can be achieved, even in large lesions, without organ resection. However, esophageal strictures are one of the major complications of ER for large superficial ESCC $[4,5]$. This complication is usually associated with dysphagia, which is followed by declining quality of life. In our previous study, mucosal defects due to ER that were larger than $3 / 4$ of the circumference of the esophagus were significantly associated with the occurrence rate of esophageal strictures when no prophylactic ing to the width of mucosal defect after ER (Group $A, \geq 3 / 4$ and $<7 / 8$; Group B, $\geq 7 / 8$ and less than the entire circumference; and Group $C$, the entire circumference). We retrospectively evaluated the stricture rate by comparing no treatment, steroid injection, or steroid injection followed by oral steroid according to the width of mucosal defect.

Results: A total of 115 patients met the selection criteria. In Group B, no treatment had a significantly higher stricture rate ( $100 \%$, vs. steroid injection: $56 \% P=0.015$; vs steroid injection followed by oral steroid: $20 \% P<0.001$ ). Conversely, in Group C, the stricture rate was high, regardless of treatment (no treatment: $100 \%$; steroid injection: $100 \%$; steroid injection followed by oral steroid: $71 \%$ ).

Conclusions: Although prophylactic steroid administration is effective to prevent strictures for $7 / 8$ circumference or larger mucosal defects, it is ineffective for whole-circumference defects. Further investigation is required.

treatment was performed [6]. Endoscopic balloon dilation (EBD) is performed with tandem repeats as a general treatment worldwide for esophageal strictures. As we previously reported, more than 6 EBD procedures were required for $66 \%$ of patients with mucosal defects larger than $3 / 4$ of the circumference of the esophageal lumen [7]. There has been a report regarding the efficacy of scheduled preventive EBD for esophageal strictures; however, the benefit of EBD for wide mucosal defects was limited $[7,8]$.

Recently, steroid administration has been reported as a prophylactic treatment to reduce esophageal strictures due to ER $[9,10]$. In these studies, promising efficacy was demonstrated; however, the studies involved a small number of subjects, and the efficacy of the combination of local steroid injection and oral steroid administration was not compared with the efficacy of local steroid in- 


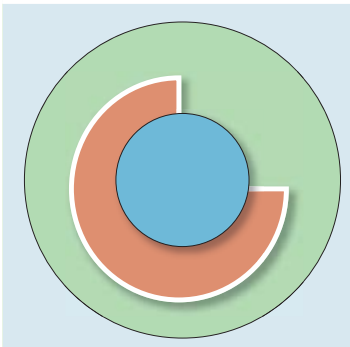

Group A: $3 / 4 \leq$ and $<7 / 8$

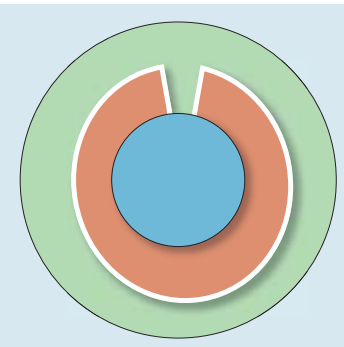

Group B: $7 / 8 \leq$ and $<1$

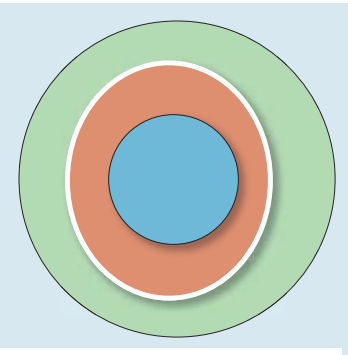

Group C: entire
Fig. 1 Groups classified according to width of mucosal defect. Patients who underwent endoscopic resection (ER) for large superficial esophageal squamous cell carcinoma (ESCC): Group A, $\geq 3 / 4$ and $<7 / 8$; Group $B, \geq 7 / 8$ and less than the entire circumference; Group $C$, the entire circumference. jection alone [9,11]. Moreover, these reports did not focus on the stricture rate according to the degree of mucosal defect lumen circumference after ER. Therefore, little is known about what width of mucosal defect should indicate prophylactic steroid treatment or what would be an appropriate method of administration to prevent stricture formation. There is also little data on populations at high risk of stenosis after ER even with prophylactic steroid treatment.

The aim of this study was to retrospectively evaluate the esophageal stricture rate among individual Groups classified according to prophylactic methods for various sized lesions of large superficial ESCC. We compared patients receiving no prophylactic treatment, steroid injection, or steroid injection followed by oral steroid according to the different widths of their mucosal defects. In addition, we analyzed the factors related to EBD for those patients whose mucosal defects were larger than $7 / 8$ of the circumference of the esophagus, which seemed to put them at high risk for stricture even with prophylactic steroid administration.

\section{Patients and methods \\ $\nabla$}

\section{Patients}

Between June 2007 and December 2013, 699 patients with 1123 superficial ESCC lesions were treated with ER at the National Cancer Center Hospital East. Of these, 149 patients with widespread mucosal defects due to ER for a solitary lesion involving 3/4 or larger than the circumference of the esophageal lumen were enrolled. The indication criteria of ER for ESCC were as follows: 1) depth invasion was limited to within SM1 in pretreatment endoscopic findings; 2) absence of lymph node or distant metastasis; 3) histologically confirmed ESCC with biopsy specimens prior to ER; and 4) provision of written informed consent. The following patients were excluded from the study: 1) those who could not be followed up for 6 months or longer; 2) those who already had a stricture due to prior ER for esophageal cancer; 3 ) those who had a history of chemoradiotherapy (CRT) for prior esophageal cancer; and 4) those who had received additional CRT or surgery after non-curative ER.

\section{Study design}

In this study, we classified all enrolled patients into 3 groups according to the width of the mucosal defect (Group $A, \geq 3 / 4$ and $<7 / 8$; Group $B, \geq 7 / 8$ and less than the entire circumference; Group C, the entire circumference), as shown in $\bullet$ Fig. 1. The circumference of the mucosal defect was retrospectively estimated with endoscopic pictures immediately after ER. The primary outcome of this study was to evaluate the occurrence of esophageal strictures within 6 months among individual groups classified according to mucosal defect or by the prophylactic methods in each Group. A stricture was defined as cases where an ordinary sized endoscope (GIF Q260, GIF 1T240; Olympus Optical Co. Ltd., Tokyo, Japan) could not pass through the post-ER site. The other outcomes were the number of EBD procedures, time to achieve EBD success, and refractory stricture rate, which are all related to EBD, so these analyses were performed for patients who received EBD in Groups B and C. The time to achieve EBD success was defined as the period from the initial EBD to the last EBD session. We evaluated the necessity of EBD among the individual steroid treatment groups (no treatment, steroid injection, and steroid injection followed by oral steroid).

\section{ER procedure}

The method of ER use in this study was strip biopsy [12] as EMR and ESD [13]. We used a single-channel upper gastrointestinal endoscope (GIF Q260J; Olympus, Tokyo, Japan), with an electrosurgical unit (ICC-200; ERBE, Tubingen, Germany) and electrosurgical knife (Dual knife KD-650L/IT knife nano KD-612; Olympus, Tokyo, Japan). We identified the tumor outlines with iodine staining and placed marker dots circumferentially outside the tumor margins using the electrosurgical knife. We injected a $0.4 \%$ sodium hyaluronic acid solution (Mucoup®; Johnson and Johnson, Tokyo, Japan) into the submucosal layer and then performed mucosal incision and submucosal dissection using the electrosurgical knife.

\section{Management after ESD for stricture prevention}

Starting in December 2009 at our institution, steroid injections into the ulcer bed due to ER were introduced for all patients with 3/4 or larger mucosal defects. Furthermore, beginning in November 2012, we commenced oral steroid administration in addition to local injections in all cases of a mucosal defect due to ER 7/8 or larger than the circumference.

For steroid injections, 1 part triamcinolone acetonide (Kenacort ${ }^{\circledR}$; $50 \mathrm{mg} / 5 \mathrm{~mL}$; Bristol-Meyers Squibb Co., Tokyo, Japan) was diluted with 2 parts saline and injected into the residual submucosal tissue of the ulcer bed, using between $0.5 \mathrm{~mL}$ and $1.0 \mathrm{~mL}$ until all $50 \mathrm{mg}$ of triamcinolone acetonide was injected. From December 2009, the sessions were performed at 3, 7, and 10 days after ER, and all $50 \mathrm{mg}$ of triamcinolone acetonide was used each time, as described previously [10]. Beginning in March 2011, a single session was undertaken at 1 day after ER, and from October 2011, immediately after ER, according to the literature report [14]. For oral steroid administration, prednisolone was started at a dose of $30 \mathrm{mg} /$ day on the third day post-ESD, tapered gradually $(30,30,25,25,20,15,10$, and $5 \mathrm{mg}$ for 7 days each), and then discontinued 8 weeks later, as Yamaguchi reported [9]. 


\section{Follow up}

Initial endoscopic examination was planned about 7 to 14 days after ESD to evaluate patients' post-ESD ulcer or stricture status. Then, regular endoscopic examination was performed at 1, 3, 6, and 12 months after ER. However, whenever patients felt dysphagia, endoscopic examination was performed on demand. When we found an esophageal stricture, EBD was subsequently performed. We used an esophageal balloon dilation catheter (CRE Fixed Wire 12-15 mm/15-18 mm, Boston Scientific Co, Boston, $\mathrm{Ma}$ ) according to the severity of the stricture. EBD was carried out using direct visualization and fluorographic monitoring [7]. The EBD procedure was repeated every 2 weeks until relief of the dysphagia and improvement of the stricture; it was then defined as a successful dilation treatment. Cases that required 6 or more EBD procedures were defined as having refractory strictures [15].

For patients with steroid injection followed by oral steroid administration, a physical examination and blood examination was performed at each regular endoscopic examination for the purpose of evaluating the side effects of the steroid.

\section{Ethical considerations}

This study was retrospective and performed at a single institution, and the protocol was approved by the institutional review board of the National Cancer Center (2013-356). All data were collected from medical records. All procedures were carried out after provision of written informed consent from the patients.

\section{Statistical Analysis}

The main focus of the current study was evaluation of 2 possible comparisons within treatment groups (no treatment vs. steroid injection, no treatment vs. steroid injection followed by oral steroid, and steroid injection vs. steroid injection followed by oral steroid). Fisher's exact test was applied to compare the stricture rate and the refractory stricture rate among each group. The time to stricture, the number of EBD procedures, and the time to achieve EBD success were compared by using the 2-sample $t$-test (variance unknown). All variables were deemed to be significant if $P \leq 0.05$. Data were analyzed using SPSS software (version 22.0 for Mac).

\section{Results \\ $\nabla$}

\section{Background characteristics of patients}

Of 149 patients with 3/4 circumference or larger mucosal defects after ER, 12 patients who received an additional CRT, 8 who received an additional surgery, 4 who had a history of CRT for prior esophageal cancer, 4 who had a stricture because of prior ER and 6 who had not been followed up for 6 months were excluded. Finally, a total of 115 patients met the selection criteria. Patient and tumor characteristics are shown in $\bullet$ Table 1. Male patients were predominant with a median age of 70 years. Six patients had received ER treatments for prior esophageal cancer and 10 other patients had a history of radiation therapy (RT) for head and neck cancer, including pharynx, larynx, and tongue cancer. However, they did not have any strictures or dysphasia after prior treatments. ESD and EMR were performed in 103 and 12 patients, respectively. The median resection size was $50 \mathrm{~mm}$ and the interquartile range (IQR) was 43.5 to $60 \mathrm{~mm}$ in diameter. The longitudinal extension of the mucosal defect were $<50 \mathrm{~mm}$ in 17 patients and $\geq 50 \mathrm{~mm}$ in 98 patients.

\begin{tabular}{|c|c|c|}
\hline & Total & $n=115$ \\
\hline \multicolumn{3}{|l|}{ Sex } \\
\hline Men & 99 & $(86 \%)$ \\
\hline Women & 16 & $(14 \%)$ \\
\hline median, IQR & 70 & $(64-73)$ \\
\hline History of ER for prior esophageal cancer & 6 & $(5 \%)$ \\
\hline $\begin{array}{l}\text { History of radiation therapy for head and neck } \\
\text { cancer }\end{array}$ & 12 & $(10 \%)$ \\
\hline \multicolumn{3}{|l|}{ Tumor location } \\
\hline Upper thoracic & 9 & $(8 \%)$ \\
\hline Middle thoracic & 57 & $(50 \%)$ \\
\hline Lower thoracic & 46 & $(40 \%)$ \\
\hline Abdominal & 3 & $(3 \%)$ \\
\hline \multicolumn{3}{|l|}{ Macroscopic type } \\
\hline 0-IIa & 1 & $(1 \%)$ \\
\hline 0 -Ilc & 114 & $(99 \%)$ \\
\hline \multicolumn{3}{|l|}{ Endoscopic resection } \\
\hline EMR & 12 & $(10 \%)$ \\
\hline ESD & 103 & $(90 \%)$ \\
\hline Tumor size (mm) & 40 & $(32-52)$ \\
\hline Resection size $(\mathrm{mm}) \quad$ median, IQR & 50 & $(43.5-60)$ \\
\hline \multicolumn{3}{|l|}{ Longitudinal extension of the mucosal defect } \\
\hline$<50 \mathrm{~mm}$ & 17 & $(15 \%)$ \\
\hline$\geq 50 \mathrm{~mm}$ & 98 & $(85 \%)$ \\
\hline \multicolumn{3}{|l|}{ Depth of tumor invasion } \\
\hline Epithelium & 26 & $(23 \%)$ \\
\hline Lamina propria mucosa & 55 & $(48 \%)$ \\
\hline Muscularis mucosa & 28 & $(24 \%)$ \\
\hline SM1 & 1 & $(1 \%)$ \\
\hline SM2 & 5 & $(4 \%)$ \\
\hline
\end{tabular}

IQR, interquartile range; EMR, endoscopic resection; ESCC, esophageal squamous cell carcinoma.

In 109 lesions, the depth of invasion was histologically limited within the mucosal layer. Of them, 2 were diagnosed as muscularis mucosa (MM) accompanied with lymphovascular infiltration. Moreover, 6 other lesions reached the submucosal layer. Finally, although a total of 8 patients required additional treatments due to non-curative resection, they received no additional therapy because of their poor physical condition.

There were 45 patients in Group A $(\geq 3 / 4$ and $<7 / 8$ of lumen mucosal defect), 45 in Group B ( $\geq 7 / 8$ and less than the entire circumference mucosal defect), and 25 in Group $C$ (the entire circumference mucosal defect) according to classification of their esophageal mucosal defects. The relationships between the groups and the prophylactic treatment for esophageal strictures are summarized in Table 2. There were a total of 33 patients with no treatment, a total of 53 patients with steroid injection, and a total of 29 patients with steroid injection followed by oral steroid administration. Of 53 patients with steroid injection, 12 patients received steroid injections at several days, and the other 41 patients received it once at 1 day after ER or immediately after ER. There were 5 patients with steroid injection followed by oral steroid in Group A. The mucosal defects of them were evaluated as $7 / 8$ circumference or larger by the operator just after ER, but were judged as less than $7 / 8$ circumference with review and classified in Group A. In Groups B and C, approximately $80 \%$ of patients received prophylactic treatments. Steroid injection alone was a major treatment in Groups A and B, whereas steroid injection followed by oral steroid was predominant in Group C. 
Prophylactic treatment

\begin{tabular}{|lrlrlrl|} 
& No treatment & Steroid injection & \multicolumn{2}{c|}{$\begin{array}{l}\text { Steroid injection followed } \\
\text { by oral steroid }\end{array}$} \\
\hline Group A $(n=45)$ & 18 & $(40 \%)$ & 22 & $(49 \%)$ & 5 & $(11 \%)$ \\
\hline Group B $(n=45)$ & 10 & $(22 \%)$ & 25 & $(56 \%)$ & 10 & $(22 \%)$ \\
\hline Group C $(n=25)$ & 5 & $(20 \%)$ & 6 & $(24 \%)$ & 14 & $(56 \%)$ \\
\hline Total $(n=115)$ & 33 & $(29 \%)$ & 53 & $(46 \%)$ & 29 & $(25 \%)$ \\
\hline
\end{tabular}

Patients were categorized by size of lesion in reference to the esophageal lumen into Group A ( $>3 / 4$ and $<7 / 8)$, Group B ( $>7 / 8$ and less than the entire circumference), and Group $C$ (the entire circumference). Treatment type was determined by the time period.
Table 2 Prophylactic treatment of each mucosal defect group.

Table 3 Stricture rate and time to stricture of each group.

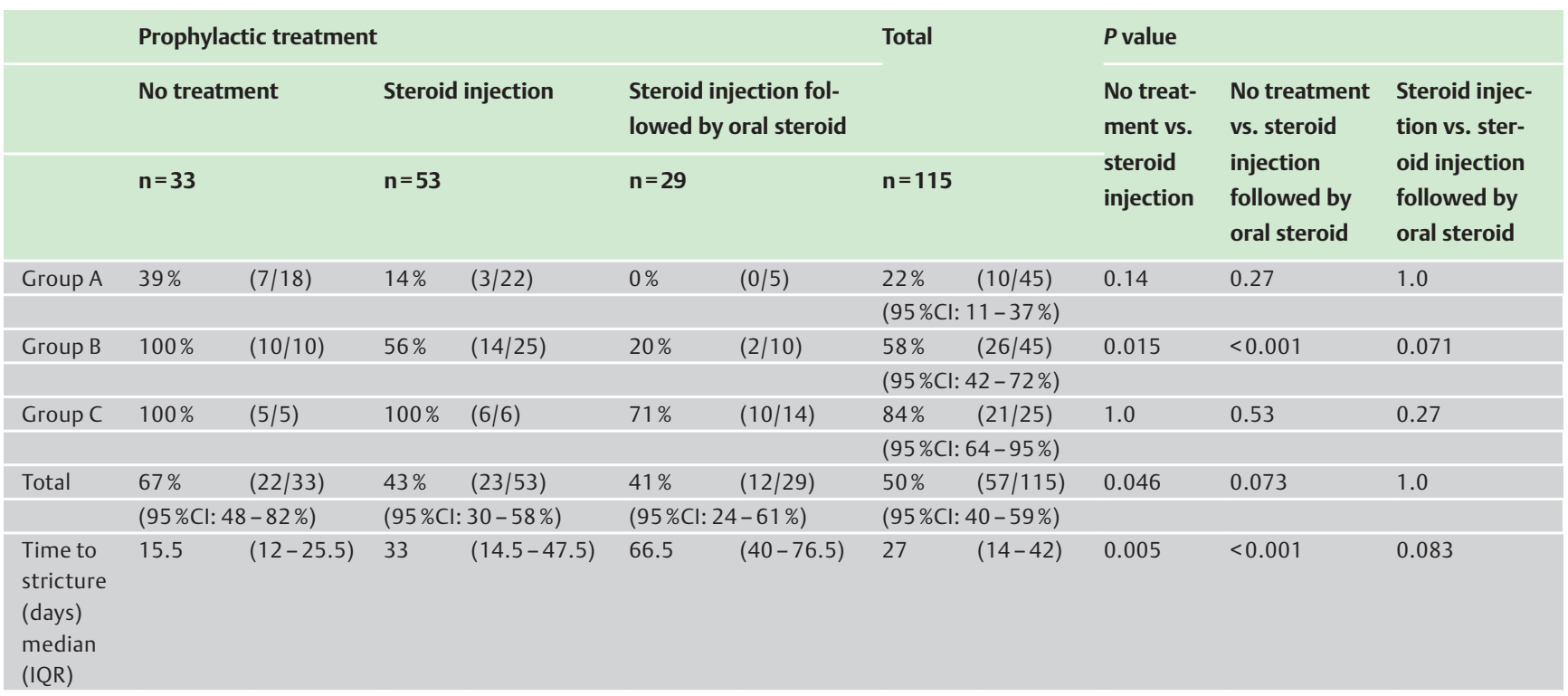

95\% Cl, 95\% confidence interval. Groups are described in Table 1.

\section{Stricture rate}

Finally, esophageal stricture was diagnosed in 57 patients. Strictures were discovered in 36 patients with planned follow-up endoscopic examination, and in the other 21 with endoscopy, on demand after the trigger symptom of dysphagia. For patients with steroid injection, the stricture rate in patients who received steroid injection over several days was $50 \%$ (6/12), and for those who received it once was $41 \%$ (17/41). There was no statistical difference between stricture rates with each steroid technique. As shown in Table 3, the stricture rate gradually increased as the width of the mucosal defect became larger. The stricture rates for Groups A, B, and C were 22\% (10/45), 58\% (26/45) (vs. Group $A, P=0.001)$, and $84 \%(21 / 25)$ (vs. Group $A, P<0.001$ and vs. Group $B, P=0.034)$, respectively. In both Groups $A$ and $B$, the stricture rate was lower in patients with steroid injection (Group A, $14 \% P=0.14$; Group B, $56 \% P=0.015$ ) compared to patients with no treatment (Group A, 39\%; Group B, 100\%). Furthermore, the stricture rate was lower in patients with steroid injection followed by oral steroid (Group A, 0\% P=1.0; Group B, 20\% P=0.071) compared to patients with steroid injection alone. Conversely, a high stricture rate was found in Group $\mathrm{C}$ regardless of prophylactic treatment (no treatment, 100\% [5/5]; steroid injection, 100\% [6/6]; steroid injection followed by oral steroid, 71\% [10/14]). The median duration to stricture was 15.5 days (IQR: $12-25.5$ ) in patients with no treatment, 33 days (IQR: $14.5-47.5$ ) in patients with steroid injection (vs no treatment, $P=0.005$ ), and 66.5 days (IQR: 40-76.5) in patients with steroid injection followed by oral steroid (vs. no treatment, $P<0.001$ and vs. steroid injection, $P=$
0.083). As shown in Table4, there was no significant difference in stricture rate according to the longitudinal extension of the mucosal defect ( $<50 \mathrm{~mm}$ vs. $\geq 50 \mathrm{~mm}$ ). Representative cases in Groups B and C are shown in $\bullet$ Fig. 2 and $\bullet$ Fig. 3.

\section{EBD for strictures due to ER}

We evaluated the patients in Groups B and C for the following items that were related to EBD: number of EBD procedures, time to achieve EBD success, and refractory stricture rate. Of 70 patients in Groups B and C, 2 patients ( 1 with no treatment and the other with steroid injection) were excluded from statistical analysis because EBD had not been performed due to surgery for pancreatic cancer or death from another disease. Finally, 68 patients were analyzed. As shown in Table 5, the median time to achieve EBD success and number of required EBD procedures was 92 days (IQR: 66-176) and 7 times (IQR: 5-12), respectively. There were significantly higher numbers of required EBD procedures in patients treated with no treatment compared with steroid injection $(P=0.046)$ and steroid injection followed by oral steroid $(P=0.002)$. Finally, 28 patients developed refractory strictures, with a refractory stricture rate of $41 \%(28 / 68)$. The refractory stricture rates among individual treatments were as follows: no treatment, 86\% (12/14); steroid injection, 33\% (10/30); and steroid injection followed by oral steroid, 25\% (6/24). Significant differences were seen between no treatment and steroid injection $(P=0.002)$ or steroid injection followed by oral steroid $(P<0.001)$. 
Table 4 Stricture rate of each group according to the longitudinal extension of the mucosal defect.

\begin{tabular}{|c|c|c|c|c|c|c|c|c|}
\hline & \multicolumn{6}{|c|}{ Prophylactic treatment } & \multicolumn{2}{|c|}{ Total } \\
\hline & \multicolumn{2}{|c|}{ No treatment } & \multicolumn{2}{|c|}{ Steroid injection } & \multicolumn{2}{|c|}{$\begin{array}{l}\text { Steroid injection followed } \\
\text { by oral steroid }\end{array}$} & & \\
\hline & \multicolumn{2}{|c|}{$n=33$} & \multicolumn{2}{|l|}{$n=53$} & \multicolumn{2}{|c|}{$n=29$} & \multicolumn{2}{|c|}{$n=115$} \\
\hline \multicolumn{9}{|l|}{ Longitudinal extension } \\
\hline$<50 \mathrm{~mm}$ & $75 \%$ & $(6 / 8)$ & $14 \%$ & $(1 / 7)$ & $50 \%$ & $(1 / 2)$ & $47 \%$ & $(8 / 17)$ \\
\hline$\geq 50 \mathrm{~mm}$ & $64 \%$ & $(16 / 25)$ & $48 \%$ & $(22 / 46)$ & $41 \%$ & $(11 / 27)$ & $50 \%$ & $(49 / 98)$ \\
\hline Total & $67 \%$ & $(22 / 33)$ & $43 \%$ & $(23 / 53)$ & $41 \%$ & $(12 / 29)$ & $50 \%$ & $(57 / 115)$ \\
\hline $\begin{array}{l}P \text { value } \\
<50 \mathrm{~mm} \mathrm{vs.} \geq 50 \mathrm{~mm}\end{array}$ & \multicolumn{2}{|l|}{0.69} & \multicolumn{2}{|l|}{0.12} & \multicolumn{2}{|l|}{1.0} & \multicolumn{2}{|l|}{1.0} \\
\hline
\end{tabular}
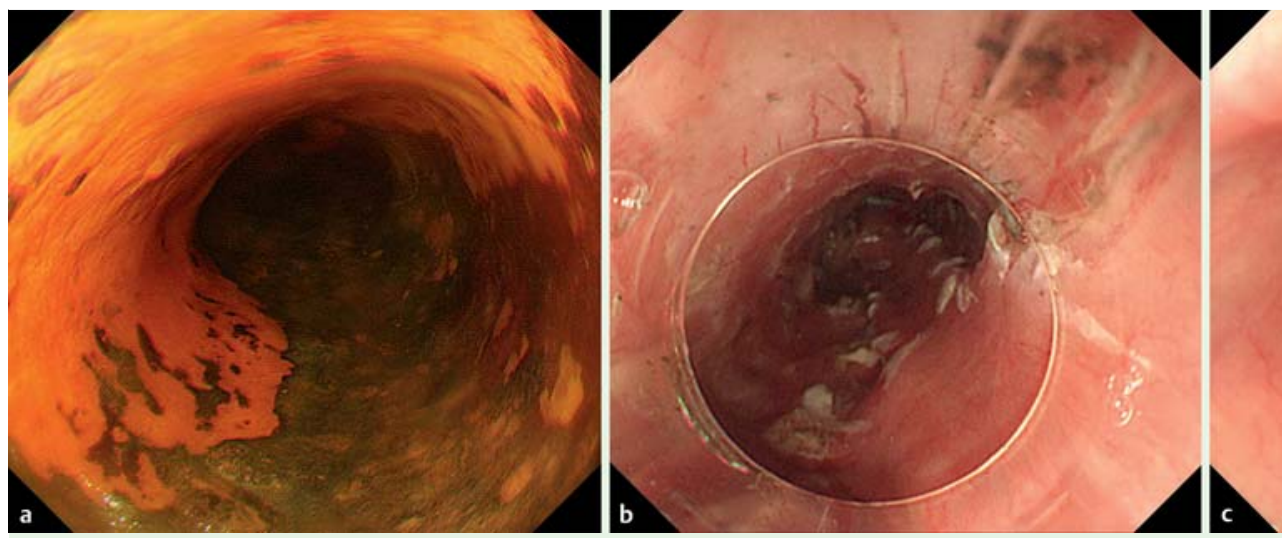

Fig. 2 Representative case (case 1). 59-year-old male who underwent endoscopic resection for large superficial esophageal squamous cell carcinoma: a Endoscopic view of the tumor after Lugol's staining. The tumor spread to about 3/4 of the circumference of the esophageal lumen. b Endoscopic view of the ulcer bed immediately after ESD. The width of the mucosal defect was $\geq 7 / 8$ and less than the entire circumference (Group B). Then, steroid injection alone was performed as a prophylactic treatment. $\mathbf{c}$ The esophageal stricture occurred at 42 days after ESD and subsequently endoscopic balloon dilation (EBD) was performed.

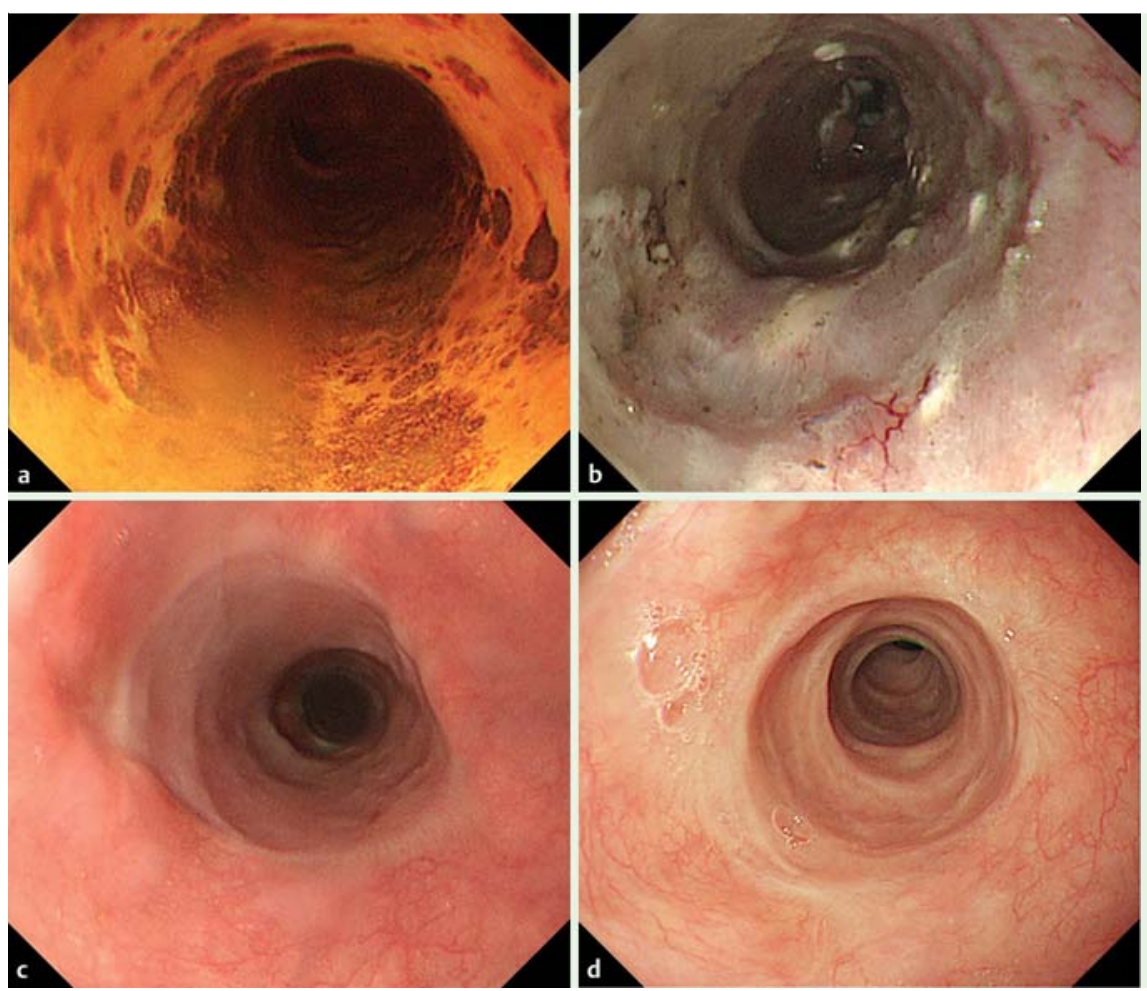

Fig. 3 Representative case (case 2). 76-year-old male who underwent endoscopic resection for large superficial esophageal squamous cell carcinoma: a Endoscopic view of the tumor after Lugol's staining. The tumor spread to about $7 / 8$ ths of the circumference of the esophageal lumen. $\mathbf{b}$ Endoscopic view of the ulcer bed immediately after ESD. The width of the mucosal defect was the entire lumen circumference (Group C). Then, steroid injection followed by oral steroid was administered as a prophylactic treatment. c Endoscopic view on the 35th day. The mucosal defect was still undergoing re-epithelialization, and an ordinary sized endoscope could pass. $\mathbf{d}$ Endoscopic view on the 120th day. The complete epithelialization is shown and an ordinary sized endoscope could pass without dysphagia. 
Table 5 Duration and number of EBD sessions.

\begin{tabular}{|c|c|c|c|c|c|c|c|}
\hline & \multicolumn{4}{|c|}{ Prophylactic treatment } & \multicolumn{3}{|l|}{$P$ value } \\
\hline & No treatment & $\begin{array}{l}\text { Steroid } \\
\text { injection }\end{array}$ & $\begin{array}{l}\text { Steroid injection } \\
\text { followed by oral } \\
\text { steroid } \\
n=24\end{array}$ & $n=68$ & $\begin{array}{l}\text { No treat- } \\
\text { ment vs. } \\
\text { steroid } \\
\text { injection }\end{array}$ & $\begin{array}{l}\text { No treatment } \\
\text { vs. steroid } \\
\text { injection } \\
\text { followed by } \\
\text { oral steroid }\end{array}$ & $\begin{array}{l}\text { Steroid injec- } \\
\text { tion vs. ster- } \\
\text { oid injection } \\
\text { followed by } \\
\text { oral steroid }\end{array}$ \\
\hline Case of stricture & 14 & 19 & 12 & 45 & & & \\
\hline $\begin{array}{l}\text { Time to achieve } \\
\text { EBD success (days) } \\
\text { median (IQR) }\end{array}$ & $173(85.8-230)$ & $84(53.5-123)$ & $92.5(64.3-129)$ & $92(66-176)$ & 0.58 & 0.053 & 0.26 \\
\hline $\begin{array}{l}\text { Number of EBD ses- } \\
\text { sions median (IQR) }\end{array}$ & $12.5(7.5-16)$ & $6(4.5-10.5)$ & $5.5(4-8.3)$ & $7(5-12)$ & 0.046 & 0.002 & 0.51 \\
\hline $1 \sim 2$ & 0 & 4 & 2 & 6 & & & \\
\hline $3 \sim 5$ & 2 & 5 & 4 & 11 & & & \\
\hline$\geq 6$ & 12 & 10 & 6 & 28 & & & \\
\hline $\begin{array}{l}\text { Refractory stricture } \\
\text { rate }\end{array}$ & $\begin{array}{l}12 / 14(86 \%) \\
(95 \% \mathrm{Cl}: 57-98 \%)\end{array}$ & $\begin{array}{l}10 / 30(33 \%) \\
(95 \% \text { Cl: } 17-53 \%)\end{array}$ & $\begin{array}{l}6 / 24(25 \%) \\
(95 \% \mathrm{Cl}: 10-47 \%)\end{array}$ & $\begin{array}{l}28 / 68(41 \%) \\
(95 \% \mathrm{Cl}: 29-54 \%)\end{array}$ & 0.002 & $<0.001$ & 0.56 \\
\hline
\end{tabular}

EBD, endoscopic balloon dilation; IQR, interquartile range; $95 \% \mathrm{Cl}, 95 \%$ confidence interval. We analyzed data for Groups B and C without Group A, and excluded the 2 cases that could not be evaluated for whether they had refractory strictures.

Finally, 5 patients in Group C could not recover from dysphagia despite tandem repeat EBD procedures. Of them, 4 patients were treated with other modalities, such as the radial incision and cutting method $[16,17]$ or biodegradable stents $[18,19]$ for their refractory strictures. The remaining patient died from advanced cancer of the tongue.

Side effects of oral steroid administration, such as diabetes mellitus, peptic ulcer, adrenal insufficiency, esophagitis, and corticosteroid psychosis were not found. Although the direct relationship between infection and opportunistic infection as a side effect was unclear, 1 patient in Group $C$ with steroid injection followed by oral steroid was diagnosed as acute pneumonia. While he had a fever of over $38^{\circ} \mathrm{C}$ and displayed wheezing at 25 days after ESD, the pneumonia was successfully cured with medical treatment at our hospital.

Regarding complications for EBD, perforation was found in 2 patients, with a perforation rate of $0.43 \%(2 / 460)$ in all EBD sessions. These 2 patients had been classified into Group C, and were administered steroid injections alone as prophylactic treatment. The onsets of their perforations were at 68 days and 84 days after ESD, and in the third and 11th EBD procedures, respectively. They recovered with only conservative treatment including antibiotics.

\section{Discussion \\ $\nabla$}

In the current study, steroid injection alone and steroid injection followed by oral steroid administration were demonstrated to be significantly effective in preventing strictures, compared with no treatment, in patients with mucosal defects after ER of 7/8 circumferences to nearly the entire lumen. However, the efficacy of steroid treatments was limited in cases with a lesion extending to the whole circumference of the esophageal lumen. In addition, prophylactic treatments, especially steroid injection followed by oral steroid, significantly led to a reduction in the required number of interventions with EBD to treat stricture in patients who had experienced post-ER esophageal strictures.
Fibrosis and scar formation occurring during the healing process is generally found in the condition of esophageal stricture $[4,6$, 20]. This process is classified into 3 phases: the acute inflammation phase, proliferation phase, and remodeling phase. It has been reported that stricture formation due to ER is hypothesized to be caused by a decrease of the esophageal wall elasticity due to fibrosis, or layers of regular horizontal arrangements of spindleshaped myoblasts $[20,21]$. Some clinical studies have shown that esophageal strictures occur approximately 2 to 4 weeks after ER procedures $[4,5]$. The mechanism of the prophylactic efficacy of steroid injection has been reported as a reduction in the appearance and proliferation of the spindle-shaped myofibroblastic cells and normalized epithelialization [21,22]. In our study, the median time to stricture was prolonged significantly in the prophylactic treatment groups. Based on these results, we suggest that systemic steroid administration may prolong the duration to stricture formation by an additional effect of delaying epithelialization.

In the current study, the stricture rate in patients with no treatment was $67 \%(22 / 33)$. In contrast, the stricture rate in patients with $3 / 4$ diameter or larger mucosal defects due to ER was $68 \%$ $(13 / 19)$ in our previous report [6]. This result from the current study was similar to that in the previous study despite completely different patients. Furthermore, the subjects in our previous study evaluating the efficacy of scheduled preventive EBD [8] included many patients with ER defects as large as the entire circumference of the lumen. Scheduled preventive EBD was so effective that it decreased the stricture rate from $92 \%$ (no treatment) to 59\% (with scheduled preventive EBD). Therefore, prophylactic steroid administration appears to be a more favorable treatment compared to scheduled preventive EBD only, because the stricture rate with any steroid administration and no preventive EBD was $43 \%$ (35/82) in the current study.

There are several reports of the efficacy of prophylactic steroid administration after ER for large ESCC. Hanaoka et al. conducted a prospective study to evaluate the efficacy of steroid injection in patients with mucosal defects $\geq 3 / 4$ diameter to nearly the entire circumference of the esophageal lumen [14]. In their study, significant differences in the frequency of strictures were represen- 
ted, and steroid treatment was quite effective for esophageal stricture due to ER. In contrast, because patients with whole-circumference mucosal defects were excluded from their study, the efficacy of steroid treatment for whole-circumference lesions is unclear. Yamaguchi et al. reported initially the efficacy of oral prednisolone administration after ER [9]. Stricture rates in semicircular ESD ( $\geq 3 / 4$ diameter to less than the entire circumference) and in complete circular ESD were $6.3 \%(1 / 16)$ and $0 \%$ $(0 / 3)$, respectively [9]. The stricture rate of patients with mucosal defects of less than the entire circumference and with oral steroid administration in their study was similar to our current results. In contrast, no esophageal strictures were found in patients with entire-circumference resections in their study. In our study, patients with entire-circumference resections showed high stricture rates in spite of the additional local steroid injection. Because the number of subjects with an entire-circumference resection was quite small, there would be some limitations to their study. Therefore, we believe that the efficacy of prophylactic steroid treatment for entire-circumference defects eventually will be elucidated. At present, we routinely performed local steroid injection for the mucosal defect after ESD that larger than 3/4ths of the circumference of the esophagus, and subsequently, oral steroid administration was added for the patients with the mucosal defect larger than 7/8ths in our practice. Furthermore, alternative effective prophylactic modalities for whole circumference defects are expected to be investigated in the near future. In the cases that were regarded as the high risk of esophageal stricture after ESD even with prophylactic treatment, CRT could be a primary treatment. And if local residual lesion was found, salvage ESD could be performed in some cases [23].

There have been explorations into other treatments for strictures as well. There was a report that showed the efficacy of scheduled EBD combined with the oral anti-allergic agent tranilast (stricture rate: $33 \%$ [5/15]) [24], the preliminary results of tissue-engineered cell sheets (stricture rate: $10 \%$ [1/10]) [25], and polyglycolic acid sheet (stricture rate: 7.7\% [1/13]) [26]. As for prophylactic esophageal stent placement after ER, results with a fully-covered metallic stent (stricture rate: 18\% [2/11]) [27] and a biodegradable stent (for porcine) [19] have been previously published. For prophylactic treatment with a steroid over a short period, there was a report about low-dose oral prednisolone (30, 20 , and $10 \mathrm{mg} /$ day in weeks 1,2 , and 3 ) that showed a stricture rate of $18 \%$ (3/17) for lesions more than $3 / 4$ circumferences including 3 cases with complete circumference [28].

Finally, this study has several limitations. First, it was a retrospective historical comparison in a single institution. Beginning in December 2009, we introduced steroid injection, and oral steroid administration in addition to steroid injection was commenced beginning in November 2012. Therefore, prophylactic steroid treatments, either steroid injection alone or steroid injection followed by oral steroid administration, were not performed during the same time periods. In addition, the number of subjects in each Group was small; therefore, the study was statistically underpowered when comparing the efficacy of each prophylactic treatment in each subgroup. Second, the efficacy of steroid injection alone was not compared with that of oral steroid administration alone. Third, patients' symptoms were not taken into the definition of esophageal stricture because we did not completely document their degree of dysphagia at every visit. Therefore, we defined the esophageal stricture only with the ability of endoscope passage in this study. Because of these limitations, prospective randomized controlled studies will be required to evaluate the efficacy of prophylactic steroid treatment and to clarify the adequate method for each width of mucosal defect.

\section{Conclusion \\ $\nabla$}

In conclusion, prophylactic steroid administration is effective for patients with 7/8 circumference or larger but not whole-diameter mucosal defects after ER. This Group may be the true target population who will benefit the most from prophylactic steroid administration. However, a higher stricture rate was found in entire-circumference defect cases regardless of prophylactic treatment. The most important next step is to clarify the factors limiting prophylactic steroid treatments in entire-circumference defect cases. If the serious complication of esophageal strictures can be avoided, patients with entire-circumference mucosal defects due to ER will have a greatly improved quality of life.

\section{Competing interests: None}

\section{Acknowledgements}

$\nabla$

This study was presented at the 22th United European Gastroentertology Week, Vienna, Austria, October 18-22, 2014.

\section{References}

1 Kuwano H, Nishimura Y, Oyama T. Guidelines for Diagnosis and Treatment of Carcinoma of the Esophagus April 2012 edited by the Japan Esophageal Society. Esophagus 2015; 12: 1 - 30

2 Oyama T, Tomori A, Hotta $K$ et al. Endoscopic submucosal dissection of early esophageal cancer. Clin Gastroenterol Hepatol 2005; 3: 67 - 70

3 Ono $S$, Fujishiro $M$, Niimi $K$ et al. Long-term outcomes of endoscopic submucosal dissection for superficial esophageal squamous cell neoplasms. Gastrointest Endosc 2009; 70: 860-866

4 Mizuta H, Nishimori I, Kuratani Yet al. Predictive factors for esophageal stenosis after endoscopic submucosal dissection for superficial esophageal cancer. Dis Esophagus 2009; 22: 626-631

5 Ono S, Fujishiro M, Niimi K et al. Predictors of postoperative stricture after esophageal endoscopic submucosal dissection for superficial squamous cell neoplasms. Endoscopy 2009; 41: 661 - 665

6 Katada C, Muto M, Manabe T et al. Esophageal stenosis after endoscopic mucosal resection of superficial esophageal lesions. Gastrointest Endosc 2003; 57: 165-169

7 Yoda Y, Yano T, Kaneko K et al. Endoscopic balloon dilatation for benign fibrotic strictures after curative nonsurgical treatment for esophageal cancer. Surg Endosc 2012; 26: 2877 - 2883

8 Ezoe $Y$, Muto M, Horimatsu $T$ et al. Efficacy of preventive endoscopic balloon dilation for esophageal stricture after endoscopic resection. J Clin Gastroenterol 2011; 45: 222-227

9 Yamaguchi $N$, Isomoto $H$, Nakayama T et al. Usefulness of oral prednisolone in the treatment of esophageal stricture after endoscopic submucosal dissection for superficial esophageal squamous cell carcinoma. Gastrointest Endosc 2011; 73: 1115-1121

10 Hashimoto S, Kobayashi M, Takeuchi M et al. The efficacy of endoscopic triamcinolone injection for the prevention of esophageal stricture after endoscopic submucosal dissection. Gastrointest Endosc 2011; 74: $1389-1393$

11 Sato H, Inoue H, Kobayashi Yet al. Control of severe strictures after circumferential endoscopic submucosal dissection for esophageal carcinoma: oral steroid therapy with balloon dilation or balloon dilation alone. Gastrointest Endosc 2013; 78: 250-257

12 Soetikno RM, Gotoda T, Nakanishi Yet al. Endoscopic mucosal resection. Gastrointest Endosc 2003; 57: 567 - 579

13 Fujishiro $M$, Yahagi $N$, Kakushima $N$ et al. Endoscopic submucosal dissection of esophageal squamous cell neoplasms. Clin Gastroenterol Hepatol 2006; 4: 688-694

14 Hanaoka $N$, Ishihara $R$, Takeuchi $Y$ et al. Intralesional steroid injection to prevent stricture after endoscopic submucosal dissection for esoph- 
ageal cancer: a controlled prospective study. Endoscopy 2012; 44: $1007-1011$

15 Kochman ML, McClave SA, Boyce HW. The refractory and the recurrent esophageal stricture: a definition. Gastrointes Endosc 2005; 62: 474475

16 Muto M, Ezoe $Y$, Yano $T$ et al. Usefulness of endoscopic radial incision and cutting method for refractory esophagogastric anastomotic stricture (with video). Gastrointest Endosc 2012; 75: 965-972

17 Yano T, Yoda Y, Satake $H$ et al. Radial incision and cutting method for refractory stricture after nonsurgical treatment of esophageal cancer. Endoscopy 2013; 45: 316-319

18 Repici A, Vleggaar FP, Hassan C et al. Efficacy and safety of biodegradable stents for refractory benign esophageal strictures: the BEST (Biodegradable Esophageal Stent) study. Gastrointest Endosc 2010; 72: 927-934

19 Pauli EM, Schomisch SJ, Furlan JP et al. Biodegradable esophageal stent placement does not prevent high-grade stricture formation after circumferential mucosal resection in a porcine model. Surg Endosc 2012; 26: 3500-3508

20 Honda M, Nakamura T, Hori Y et al. Process of healing of mucosal defects in the esophagus after endoscopic mucosal resection: histological evaluation in a dog model. Endoscopy 2010; 42: $1092-1095$

21 Nonaka K, Miyazawa M, Ban S et al. Different healing process of esophageal large mucosal defects by endoscopic mucosal dissection between with and without steroid injection in an animal model. BMC gastroenterology 2013; 13: 72
22 Honda M, Nakamura T, Hori $Y$ et al. Feasibility study of corticosteroid treatment for esophageal ulcer after EMR in a canine model. J Gastroenterol 2011; 46: 866-872

23 Yano T, Muto M, Hattori S et al. Long-term results of salvage endoscopic mucosal resection in patients with local failure after definitive chemoradiotherapy for esophageal squamous cell carcinoma. Endoscopy 2008; 40: 717-721

24 Uno K, Iijima K, Koike T et al. A pilot study of scheduled endoscopic balloon dilation with oral agent tranilast to improve the efficacy of stricture dilation after endoscopic submucosal dissection of the esophagus. Journal Clin Gastroenterol 2012; 46: e76 - 82

25 Ohki T, Yamato $M$, Ota $M$ et al. Prevention of esophageal stricture after endoscopic submucosal dissection using tissue-engineered cell sheets. Gastroenterology 2012; 143: 582 - 588 e581-582

26 Iizuka T, Kikuchi D, Yamada A et al. Polyglycolic acid sheet application to prevent esophageal stricture after endoscopic submucosal dissection for esophageal squamous cell carcinoma. Endoscopy 2015; 47: $341-344$

27 Wen J, Yang Y, Liu Q et al. Preventing stricture formation by covered esophageal stent placement after endoscopic submucosal dissection for early esophageal cancer. Digest Dis Sci 2014; 59: 658 -663

28 Kataoka M, Anzai S, Shirasaki T et al. Efficacy of short period, low dose oral prednisolone for the prevention of stricture after circumferential endoscopic submucosal dissection (ESD) for esophageal cancer. Endosc Int Open 2015; 3: E113-117 